\title{
Optimizing microbiome sequencing for small intestinal aspirates: validation of novel techniques through the REIMAGINE study
}

Gabriela Guimaraes Sousa Leite', Walter Morales', Stacy Weitsman', Shreya Celly', Gonzalo Parodi', Ruchi Mathur ${ }^{1,2}$, Rashin Sedighi ${ }^{1}$, Gillian M. Barlow ${ }^{1}$, Ali Rezaie ${ }^{1,3}$ and Mark Pimentel ${ }^{1,3^{*}}$ (D)

\begin{abstract}
Background: The human small intestine plays a central role in the processes of digestion and nutrient absorption. However, characterizations of the human gut microbiome have largely relied on stool samples, and the associated methodologies are ill-suited for the viscosity and low microbial biomass of small intestine samples. As part of the REIMAGINE study to examine the specific roles of the small bowel microbiome in human health and disease, this study aimed to develop and validate methodologies to optimize microbial analysis of the small intestine.

Results: Subjects undergoing esophagogastroduodenoscopy without colon preparation for standard of care were prospectively recruited, and $\sim 2 \mathrm{ml}$ samples of luminal fluid were obtained from the duodenum using a custom sterile aspiration catheter. Samples of duodenal aspirates were either untreated (DA-U, $N=127)$ or pretreated with dithiothreitol (DA-DT, $N=101)$, then cultured on MacConkey agar for quantitation of aerobic gram-negative bacteria, typically from the class Gammaproteobacteria, and on blood agar for quantitation of anaerobic microorganisms. DA-DTT exhibited 2.86-fold greater anaerobic bacterial counts compared to DA-U $(P=0.0101)$, but were not statistically different on MacConkey agar.

DNA isolation from DA-U $(N=112)$ and DA-DTT $(N=43)$ samples and library preparation for 165 rRNA gene sequencing were also performed using modified protocols. DA-DTT samples exhibited 3.81-fold higher DNA concentrations $(P=0.0014)$ and 4.18 -fold higher $16 S$ library concentrations $(P<0.0001)$ then DA-U samples. 16S rRNA gene sequencing revealed increases in the detected relative abundances of obligate and facultative anaerobes in DADTT samples, including increases in the genera Clostridium (false discovery rate (FDR) $P=4.38 \mathrm{E}-6$ ), Enterococcus (FDR $P=2.57 \mathrm{E}-8$ ), Fusobacterium (FDR $P=0.02$ ) and Bacteroides (FDR $P=5.43 \mathrm{E}-9$ ). Detected levels of Gram-negative enteropathogens from the phylum Proteobacteria, such as Klebsiella (FDR $P=2.73 \mathrm{E}-6)$ and Providencia (FDR $P<0.0001$ ) (family Enterobacteriaceae) and Pseudomonas (family Pseudomonadaceae) (FDR $P=0.04$ ), were also increased in DA-DTT samples.
\end{abstract}

Conclusions: This study validates novel DTT-based methodology which optimizes microbial culture and 165 rRNA gene sequencing for the study of the small bowel microbiome. The microbial analyses indicate increased isolation of facultative and obligate anaerobes from the mucus layer using these novel techniques.

Keywords: Small intestine, Microbiome, Mucus layer, Methodology optimization, Microbial culture, 16S rRNA gene sequencing

\footnotetext{
* Correspondence: pimentelm@cshs.org

'Medically Associated Science and Technology (MAST) Program, Cedars-Sinai

Medical Center, Los Angeles, CA, USA

${ }^{3}$ Division of Digestive and Liver Diseases, Cedars-Sinai Medical Center, Los

Angeles, CA, USA

Full list of author information is available at the end of the article
}

(c) The Author(s). 2019 Open Access This article is distributed under the terms of the Creative Commons Attribution 4.0 International License (http://creativecommons.org/licenses/by/4.0/), which permits unrestricted use, distribution, and reproduction in any medium, provided you give appropriate credit to the original author(s) and the source, provide a link to the Creative Commons license, and indicate if changes were made. The Creative Commons Public Domain Dedication waiver (http://creativecommons.org/publicdomain/zero/1.0/) applies to the data made available in this article, unless otherwise stated. 


\section{Background}

The Human Microbiome Project [1] was a groundbreaking introduction to the understanding of the microbiome of the human body. In this effort, many areas of the human microbiome were sampled and characterized, such as the mouth, nose, integument and vaginal tract [2]. The gastrointestinal tract was specifically characterized using stool as an easily available surrogate. Although stool sequencing may reveal the microbial signature of the distal colon, it is well known that stool does not adequately represent the entire gastrointestinal tract, given the multiple environments that exist as one travels from the stomach to the small bowel and then the colon [3]. For example, conditions such as acidity and transit time vary tremendously along the intestine with likely significant effects on microbes by area of exam [3].

In contrast to the colon, the small intestine, which is divided into the duodenum, jejunum and ileum, is of central importance to digestion and nutrient absorption. Of these, the duodenum has great importance as the site of convergence of chyme from the stomach, enzymes from the pancreas and bile salts from the gall bladder. Clearly, characterizing the microbial populations of the small intestine is of central importance, but efforts to date have been hampered both by the difficulty of obtaining samples, and by challenges associated with adapting sample processing for DNA isolation techniques that were designed for stool.

The REIMAGINE (Revealing the Entire Intestinal Microbiota and its Associations with the Genetic, Immunologic, and Neuroendocrine Ecosystem) study is a large-scale initiative to examine the specific importance of the small bowel microbiome in human health and disease (https://www.cedars-sinai.org/programs/di gestive-liver-diseases/clinical/small-bowel-diseases-nutri tion/clinical-trials/small-intestinal-sampling-study.html). However, in order to adequately assess the small bowel, techniques need to be assessed and optimized for this location of the intestinal tract. In addition to maintaining sterility and preventing cross-contamination with oral and stomach microbes, particular challenges associated with processing and isolation of DNA from small intestinal samples include the viscosity, small sample volumes, and low microbial biomass. Recently, techniques and adaptations have been described aimed at optimizing DNA sequencing from low-biomass [4], but not high viscosity samples. Viscosity of the small bowel mucous could impede or affect DNA isolation. One possible remedy would be to reduce viscosity prior to DNA isolation by treating the aspirates with dithiothreitol (DTT), which is commonly used to reduce the disulfide bonds between cysteine residues of proteins and can also reduce the disulfide bonds linking mucin subunits in mucus, improving bacterial recovery and DNA extraction methods [5]. DTT has previously been used to liquefy sputum samples for DNA extraction [5].

In this study we attempt to develop and validate methodologies to optimize microbial analysis of the small intestine as part of the REIMAGINE study. Optimization included utilization of a new catheter technique for aspiration, steps to improve DNA recovery using DTT, and a new DNA library preparation technique in comparison to conventional DNA isolation and sequencing.

\section{Results}

\section{Samples and treatment}

A total of 228 subjects had DA samples collected and analyzed as shown in Fig. 1. Of these, 127 DA were not pretreated with DTT prior to microbial culture (DA-U,

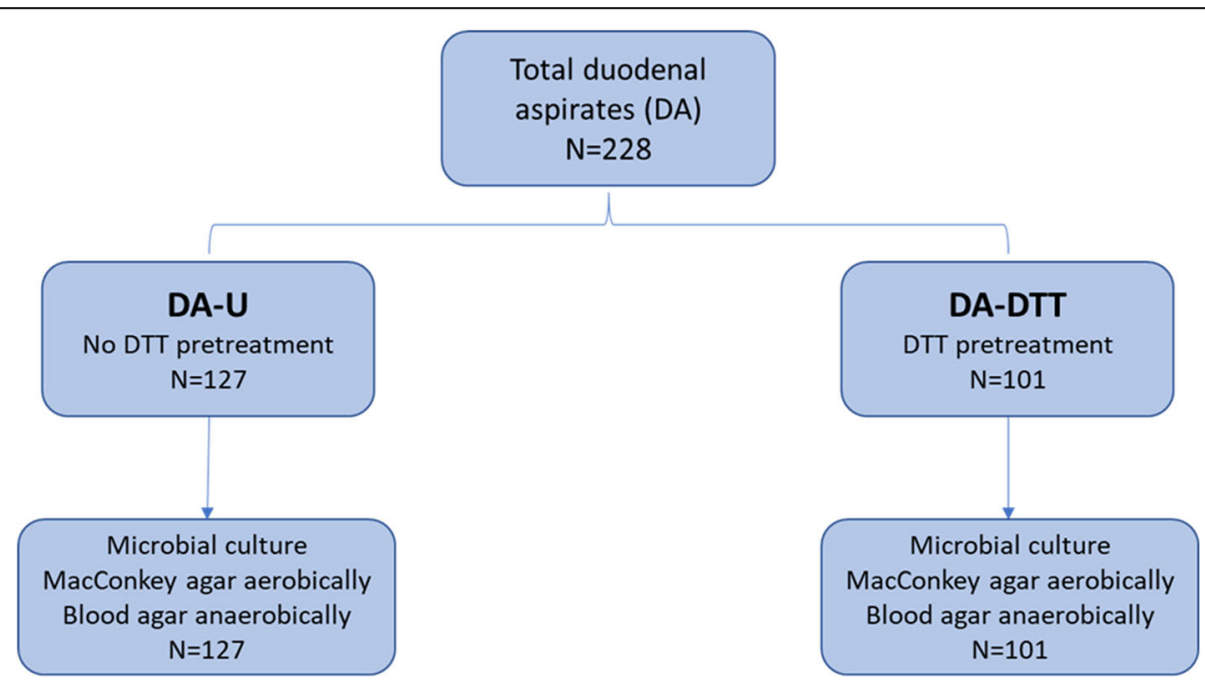

Fig. 1 Workflow for pretreatment and microbial culture, including the number of subjects in each group 
the untreated group), and 101 were pretreated with DTT prior to microbial culture (the DA-DTT group).

\section{DTT effect on microbial cultures}

No growth was observed in MacConkey agar plated with $1 \mathrm{x}$ DTT only (negative control). The CFU on MacConkey agar obtained from DA-U subjects ranged from 0 to $240 \times 10^{3} \mathrm{CFU} / \mathrm{mL} \quad\left(\right.$ Mean $=10.6 \times 10^{3} \mathrm{CFU} / \mathrm{mL}$, Median $=0 \mathrm{CFU} / \mathrm{mL}$, 25th percentile $=0 \mathrm{CFU} / \mathrm{mL}$ and 75 th percentile $=0 \mathrm{CFU} / \mathrm{mL}$ ). In the DA-DTT group, the CFU on MacConkey agar ranged from 0 to $1035 \times 10^{3} \mathrm{CFU} /$ $\mathrm{mL} \quad\left(\right.$ Mean $=28.22 \times 10^{3} \mathrm{CFU} / \mathrm{mL}, \quad$ Med $=0 \mathrm{CFU} / \mathrm{mL}$, 25th percentile $=0 \mathrm{CFU} / \mathrm{mL}$ and 75 th percentile $=2.5 \times$ $10^{3} \mathrm{CFU} / \mathrm{mL}$ ) (Additional file 1). For the purposes of statistical analysis only, no growth was designated as 1 bacterial CFU/mL of aspirate. DA-DTT exhibited 2.6fold greater bacterial colonies on MacConkey agar when compared to DA-U, but the $p$-value did not reach statistical significance $(P=0.14)$.

No growth was observed on blood agar cultured with $1 x$ DTT only (negative control). The CFU on blood agar obtained from DA-U subjects ranged from 0 to $800 \times$ $10^{3} \mathrm{CFU} / \mathrm{mL}\left(\right.$ Mean $=31.3 \times 10^{3} \mathrm{CFU} / \mathrm{mL}$, Median $=0$ $\mathrm{CFU} / \mathrm{mL}$, 25th percentile $=0 \mathrm{CFU} / \mathrm{mL}$ and 75 th percentile $=20 \times 10^{3} \mathrm{CFU} / \mathrm{mL}$ ) (Additional file 1). On blood agar, DA-DTT exhibited 2.86-fold greater anaerobic bacterial colonies when compared to DA-U $(P=0.0101)$. For the purposes of statistical analysis only, no growth was designated as 1 bacterial $\mathrm{CFU} / \mathrm{mL}$ of aspirate. In the DA-DTT group, CFU on blood agar ranged from 0 to $2070 \times 10^{3} \mathrm{CFU} / \mathrm{ml}\left(\right.$ Mean $=89.58 \times 10^{3} \mathrm{CFU} / \mathrm{mL}$, Med $=$ $6 \times 10^{3} \mathrm{CFU} / \mathrm{mL}$, 25th percentile $=0 \mathrm{CFU} / \mathrm{mL}$ and 75 th percentile $=98.5 \times 10^{3} \mathrm{CFU} / \mathrm{mL}$ ).

\section{Immediate post aspiration DTT improves DNA extraction and 165 metagenomic library preparation for $D A$}

A total of 155 subjects had their DA samples sequenced and analyzed as shown in Fig. 2 (Additional file 1). The concentrations of DNAs obtained from negative controls (DTT only) were undetectable. The concentrations of DNAs obtained from DA-U subjects ranged from undetectable levels (lower than $10 \mathrm{pg} / \mu \mathrm{L})(n=18)$ to 24.6 $\mathrm{ng} / \mu \mathrm{L} \quad(\mathrm{Med}=0.0908 \mathrm{ng} / \mu \mathrm{L}, 25$ th percentile $=0.02365$ $\mathrm{ng} / \mu \mathrm{L}$ and 75 th percentile $=0.6875 \mathrm{ng} / \mu \mathrm{L}$ ) (Additional file 1). Treatment with DTT improved DNA isolation. In the DA-DTT group, DNA concentrations ranged from undetectable levels $(n=3)$ to $68.8 \mathrm{ng} / \mu \mathrm{L}(\mathrm{Med}=0.346$ $\mathrm{ng} / \mu \mathrm{L}$, 25th percentile $=0.0906 \mathrm{ng} / \mu \mathrm{L}$ and 75 th percentile $=1.91 \mathrm{ng} / \mu \mathrm{L})$ and were 3.81 -fold higher than those from DA-U (Mann Whitney $P=0.0014$ ).

The concentrations of the final $16 \mathrm{~S}$ libraries amplified from negative controls were undetectable. The concentrations of the final $16 \mathrm{~S}$ libraries amplified from DA-U samples (i.e. those for which DTT was added only for the removal of the All Protect reagent) ranged from $0.14 \mathrm{ng} / \mu \mathrm{L}$ to $136 \mathrm{ng} / \mu \mathrm{L} \quad($ median $=21.8 \mathrm{ng} / \mu \mathrm{L}, \quad 25$ th

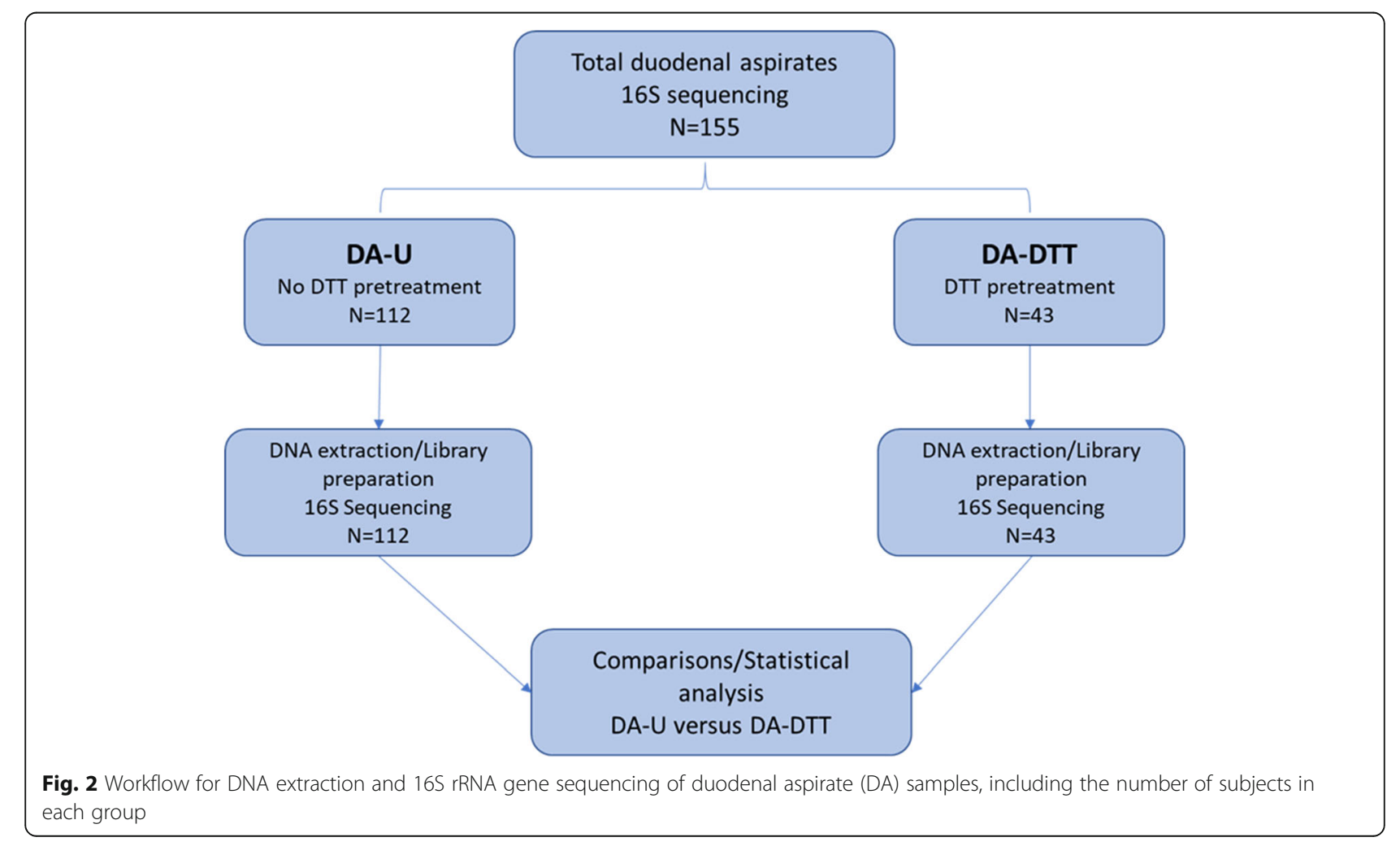


percentile $=5.1 \mathrm{ng} / \mu \mathrm{L}$ and 75 th percentile $=69.8 \mathrm{ng} / \mu \mathrm{L}$ ) and correlated with the initial DNA concentrations (Spearman $\mathrm{r}=0.316, \mathrm{P}=0.001$ ) (Additional file 1).

The concentrations of the final $16 \mathrm{~S}$ libraries amplified from DA-DTT samples (i.e. those for which DTT was added both before microbial culture and for removal of the All Protect reagent) were 4.18x higher than those of libraries from DA-U samples $(P<0.0001)$ (see Fig. 3$)$. The library concentrations ranged from $1.69 \mathrm{ng} / \mu \mathrm{L}$ to $302 \mathrm{ng} / \mu \mathrm{L}(\mathrm{Med}=91.2 \mathrm{ng} / \mu \mathrm{L}, 25$ th percentile $=36.6 \mathrm{ng} /$ $\mu \mathrm{L}$ and 75 th percentile $=117 \mathrm{ng} / \mu \mathrm{L}$ ) and correlated with the initial DNA concentrations (Spearman $\mathrm{r}=0.443, P=$ 0.003) (Additional file 1).

\section{Sequencing results}

All samples had at least 9000 sequences and no exclusions were performed. A total of 112 DA-U and 43 DA-DTT samples were sequenced. The difference in average library sizes between the groups was less than 2-fold (Additional file 2). Predictions for significant differentially abundant Operational Taxonomic Units (OTUs) were performed following recommendations from McMurdie and Holmes [6], and from Weiss et al. [7], used when the average library size for each group is approximately equal and/or the fold difference between groups is not high (> 2-3x on average) (Additional file 1).

Considering observations regarding contamination of DNA extraction kits with traces of bacterial DNA [8], $16 \mathrm{~S}$ sequencing was also performed on negative control samples (DTT only). Less than $0.03 \%$ of the total sequences generated in each MiSeq run was assigned to negative control samples, 4433 sequences on average. $27.63 \%$ of the sequences assigned to negative controls were identified as bacterial DNA, mostly belong to the Pseudomonas genus OTU 646549 (63.5\%), and Bacteroides genus OTUs 1,749,079, 193,591 and 359,538 (12\%).

All OTUs observed in negative controls were also detected in both groups analyzed, DA-U and DA-DTT. The OTUs assigned to Bacteroides genus observed in negative controls represented less than $3 \%$ of all OTUs assigned to this same genus in DA-U and DA-DTT, thus these OTUs were not excluded during downstream analysis. The OTU assigned to Pseudomonas genus (646549) observed in negative controls represented $67 \%$ of the OTUs assigned to this same genus in DA-U and DA-DTT, and considering the high risk of bias during analysis the OTU 646549 was excluded during comparisons between DA-U and DA-DTT groups (Additional file 1).

\section{$16 S$ final library concentration DA-U versus DA-DTT}

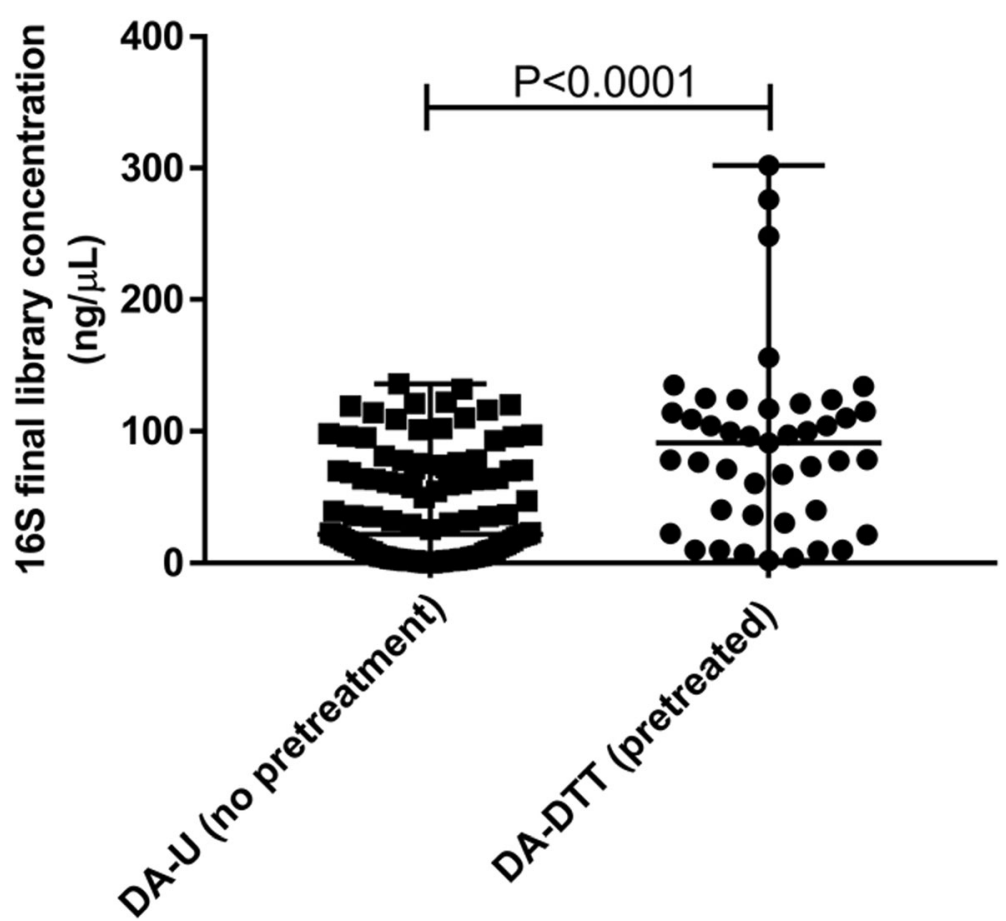

Fig. 3 Final quantification of 165 libraries from DA-U $(N=112)$ and DA-DTT $(N=43)$ samples after 35 PCR cycles. The Mann-Whitney test was used to compare the median value of groups 


\section{$D T T$ increases the detected relative abundance of anaerobic} bacteria in $D A$

The main two dominant phyla observed in DA-DTT and DA-U were Firmicutes and Proteobacteria, followed by smaller proportions of Actinobacteria, Fusobacteria, Bacteroidetes and TM7 (Fig. 4, Table 1). After pretreatment with DTT, DA showed increased relative abundance of the phyla Proteobacteria $(\mathrm{FC}=6.22$, FDR $P=$ 7.71E-7), Bacteroidetes ( $\mathrm{FC}=2.19$, FDR $P=0.03$ ) and Fusobacteria $(\mathrm{FC}=1.96$, FDR $\mathrm{P}=0.03)$, when compared to DA-U (Table 1). There were also smaller changes in the relative abundances of Actinobacteria and TM7 that did not reach significance (Table 1 ).

Although no changes were seen in the detected relative abundances of Clostridia and Bacilli, the two main classes from the phylum Firmicutes, in DA-DTT vs. DA$\mathrm{U}$, specific increases were observed in families from both of these classes. Specifically, DA-DTT exhibited increased detected relative abundances of the family Clostridiaceae $(\mathrm{FC}=5.10, \quad \mathrm{FDR} \quad \mathrm{P}<0.0001)$ and genus Clostridium ( $\mathrm{FC}=4.06$, FDR $\mathrm{P}=4.38 \mathrm{E}-6)$, which are Gram-positive obligate anaerobes, and of the family Enterococcaceae $(\mathrm{FC}=76.22$, FDR $P=2.62 \mathrm{E}-11)$ and genus Enterococcus ( $\mathrm{FC}=42.18$, FDR $\mathrm{P}=2.57 \mathrm{E}-8)$, which are Gram-positive facultative anaerobic lactic acid bacteria (Table 2, Fig. 4).

The detected relative abundances of several obligate anaerobic bacteria were increased in DA-DTT vs. DA-U, including Fusobacterium (phylum Fusobacteria), which are Gram-negative bacilli $(\mathrm{FC}=2.29$, FDR $P=0.02)$, and Bacteroides (phylum Bacteroidetes) $(\mathrm{FC}=28.08, \quad \mathrm{FDR}$ $P=5.43 \mathrm{E}-9$ ) (Table 2, Fig. 4).

\section{Pretreatment with DTT increased the detected relative abundance of gram-negative enteropathogens from the phylum Proteobacteria}

The relative abundance of the phylum Proteobacteria, a major phylum of Gram-negative bacteria, detected in DA-DTT was increased compared to that detected in $\mathrm{DA}-\mathrm{U}(\mathrm{FC}=6.22$, FDR $\mathrm{P}=7.71 \mathrm{E}-7)$. The detected relative abundances of three of the five most important classes from this phylum were significantly increased in DA-DTT compared to DA-U - class Gammaproteobacteria, which comprises several enteropathogens (FC= 8.44, FDR $P=4.25 \mathrm{E}-8$ ) [9], class Alphaproteobacteria, which includes mainly phototrophic bacteria $(\mathrm{FC}=7.94$, FDR $P=2.60 \mathrm{E}-8)$, and class Deltaproteobacteria, which includes sulfate- and sulfur-reducing bacteria $(\mathrm{FC}=6.35$, FDR $P=9.7 \mathrm{E}-5)$ (Table 3$)$. Smaller changes in classes Betaproteobacteria and Epsilonproteobacteria did not reach significance (Table 3 ).

The increase in the detected relative abundance of Gammaproteobacteria in DA-DTT was partially driven by higher detected relative abundances of Enterobacteriaceae family members ( $\mathrm{FC}=5.46$, FDR $P=1.47 \mathrm{E}-3)$, including important enteropathogens and pathogens that cause infection in several parts of the human body, such as Klebsiella and Providencia (see Table 4) [10]. The

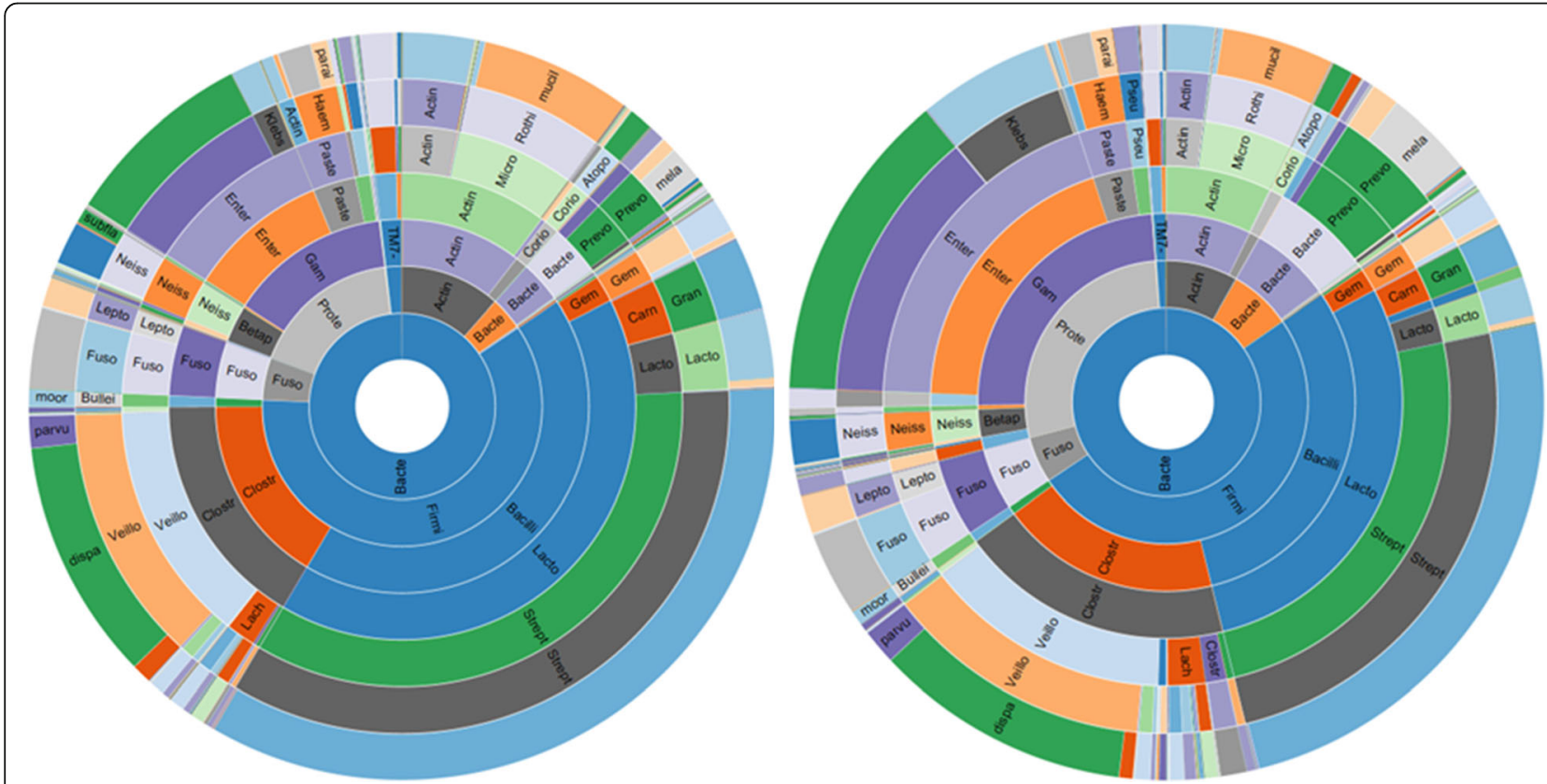

Fig. 4 Sunburst representation of the overall distribution of the small intestinal microbiome as determined by $165 \mathrm{rRNA}$ sequencing. On the left: Relative microbial abundance detected in DA-U (no pretreatment, $N=112$ ). On the right: Relative microbial abundance detected in DA-DT (pretreatment with DTT, $N=43$ ) 
Table 1 Differential abundance of the top six phyla in DA-DTT versus DA-U

\begin{tabular}{|c|c|c|c|c|c|}
\hline \multirow[b]{2}{*}{ Taxonomy } & \multicolumn{5}{|c|}{ DA-DTT $(n=43)$ versus DA-U $(n=112)$} \\
\hline & $\begin{array}{l}\text { Average Relative } \\
\text { abundance } \% \\
\text { DA-DTT }^{\mathrm{a}}\end{array}$ & $\begin{array}{l}\text { Average Relative } \\
\text { abundance } \% \\
D A-U^{\text {a }}\end{array}$ & $\begin{array}{l}\text { Fold Change } \\
\text { (calculated } \\
\text { from the GLM) }\end{array}$ & $P$-value & FDR $P$-value \\
\hline Firmicutes & 49.3 & 62.25 & 1.05 & 0.65 & 0.70 \\
\hline Proteobacteria & 28.97 & 14.8 & 6.22 & $1.4 \mathrm{E}-7$ & 7.71E-7 \\
\hline Actinobacteria & 8.91 & 12.02 & -1.23 & 0.21 & 0.42 \\
\hline Fusobacteria & 5.36 & 3.93 & 1.96 & 0.01 & 0.03 \\
\hline Bacteroidetes & 6.16 & 4.63 & 2.19 & 0.01 & 0.03 \\
\hline TM7 & 1.17 & 1.86 & -1.34 & 0.32 & 0.48 \\
\hline
\end{tabular}

$P$-value $<0.05$ and FDR $P$-value $<0.05$ are shown in bold. ${ }^{\text {a }}$ The relative abundances were calculated from the original counts (number of sequences in the OTU table). ${ }^{b}$ Fold changes were calculated from the GLM, which corrects for differences in library size between the samples and the effects of confounding factors. It is therefore not possible to derive these fold changes from the original counts (number of sequences in the OTU table) by simple algebraic calculations

detected relative abundances of other members of the class Gammaproteobacteria were also increased in DADTT vs. DA-U, including the family Aeromonadaceae (FC=63.61, FDR $P=1.18 \mathrm{E}-13)$ and the genus Pseudomonas (family Pseudomonadaceae) $(\mathrm{FC}=2.65$, FDR $P=$ $0.04)$.

The increase in detected relative abundances of Alphaproteobacteria and Deltaproteobacteria in DA-DTT (Table 3) was driven by increases in detection of the order Rhizobiales (FC $=19.03$, FDR $P=4.33 \mathrm{E}-13$ ), and of sulfur-producing bacteria from the orders Desulfobacterales $(\mathrm{FC}=42.61$, FDR $P<0.0001)$ and Desulfovibrionales (FC $=6.41$, FDR $P=6.71 \mathrm{E}-3$ ), respectively.

\section{Pretreatment with DTT does not affect microbial diversity in $D A$}

Sample rarefaction curves showed a similar pattern, which verified that most of the species present in each sample from DA-DTT and DA-U groups were observed (Fig. 5) [11]. DA-DTT exhibited the same alpha diversity as DA-U, as demonstrated by Simpson's index $(P=$ $0.9287)$ and Shannon entropy $(P=0.8066)$ (Fig. 6). Beta diversity of the DA-U and DA-DTT microbiome was analyzed based on the weighted UniFrac metric. Principal Coordinate Analysis plot showed no clustering of the DA-DTT $(n=43)$ and DA-U groups $(n=112)$ (see Fig. 7).

\section{Discussion}

In this paper, we develop and validate a novel methodological approach based on the use of the reducing agent dithiothreitol (DTT) that resolves issues related to low microbial biomass from luminal duodenal aspirates (DA). The use of DTT clearly increases the number of bacteria detected on culture plates, and also increases DNA yields and the concentration of V3/V4 libraries for sequencing, which in turn results in important differences in the microbial populations detected in DA.

Given the central role of the small intestine in the processes of digestion and nutrient absorption, accurate characterization of the human small intestinal microbiome is an important future consideration. The small intestine is not as heavily colonized as the large intestine, ranging under healthy conditions from $10^{3}$ to $10^{4}$

Table 2 Differential abundance of anaerobic bacteria in DA-DTT versus DA-U

\begin{tabular}{|c|c|c|c|c|c|}
\hline \multirow[b]{2}{*}{ Taxonomy } & \multicolumn{5}{|c|}{ DA-DTT $(n=43)$ vs. DA-U $(n=112)$} \\
\hline & $\begin{array}{l}\text { Average Relative } \\
\text { abundance } \% \\
\text { DA-DTT }\end{array}$ & $\begin{array}{l}\text { Average Relative } \\
\text { abundance \% } \\
D A-U^{a}\end{array}$ & $\begin{array}{l}\text { Fold Change } \\
\text { (calculated from } \\
\text { the } G L M)^{b}\end{array}$ & $P$-value & $\begin{array}{l}\text { FDR } \\
P \text {-value }\end{array}$ \\
\hline $\begin{array}{l}\text { P_Firmicutes, c_Clostridia, f_Clostridiaceae, } \\
\text { g_Clostridium }\end{array}$ & 0.032 & 0.024 & 4.06 & $1.22 \mathrm{E}-6$ & $4.38 \mathrm{E}-6$ \\
\hline $\begin{array}{l}\text { P_Firmicutes, c_Bacilli, f_Enterococcaceae, } \\
\text { g_Enterococcus }\end{array}$ & 0.661 & 0.009 & 42.18 & 5.57E-9 & 2.57E-8 \\
\hline $\begin{array}{l}\text { P_Fusobacteria, c_Fusobacteriia, f_- } \\
\text { Fusobacteriaceae, g_Fusobacterium }\end{array}$ & 3.625 & 2.471 & 2.29 & 0.01 & 0.02 \\
\hline $\begin{array}{l}\text { p_Bacteroidetes, c_Bacteroidia, } \\
\text { f_Bacteroidaceae, g_Bacteroides }\end{array}$ & 0.626 & 0.073 & 28.08 & $1.08 \mathrm{E}-9$ & $5.43 E-9$ \\
\hline
\end{tabular}

$P$-value $<0.05$ and FDR $P$-value $<0.05$ are shown in bold. ${ }^{a}$ The relative abundances were calculated from the original counts (number of sequences in the OTU table). ${ }^{b}$ Fold changes were calculated from the GLM, which corrects for differences in library size between the samples and the effects of confounding factors. It is therefore not possible to derive these fold changes from the original counts (number of sequences in the OTU table) by simple algebraic calculations 
Table 3 Differential abundance of members of the phylum Proteobacteria in DA-DTT versus DA-U

\begin{tabular}{|c|c|c|c|c|c|}
\hline \multirow[b]{2}{*}{ Taxonomy } & \multicolumn{5}{|c|}{ DA-DTT $(n=43)$ vs. DA-U $(n=112)$} \\
\hline & $\begin{array}{l}\text { Average relative } \\
\text { abundance \% } \\
\text { DA-DTT }\end{array}$ & $\begin{array}{l}\text { Average relative } \\
\text { abundance \% } \\
D A-U^{\mathrm{a}}\end{array}$ & $\begin{array}{l}\text { Fold Change } \\
\text { (calculated from } \\
\text { the GLM) }\end{array}$ & $P$-value & $\begin{array}{l}\text { FDR } \\
P \text {-value }\end{array}$ \\
\hline p_Proteobacteria, c_Gammaproteobacteria & 23.823 & 10.492 & 8.44 & $8.3 \mathrm{E}-9$ & $4.25 \mathrm{E}-8$ \\
\hline P_Proteobacteria, c_Alphaproteobacteria & 1.294 & 0.145 & 7.94 & 4.05E-9 & $2.60 \mathrm{E}-8$ \\
\hline p_Proteobacteria, c_Deltaproteobacteria & 0.008 & 0.001 & 6.35 & $3.08 \mathrm{E}-5$ & $9.70 \mathrm{E}-5$ \\
\hline P_Proteobacteria, c_Betaproteobacteria & 3.569 & 4.029 & -1.26 & 0.41 & 0.56 \\
\hline P_Proteobacteria, C_Epsilonproteobacteria & 0.281 & 0.167 & 1.74 & 0.14 & 0.29 \\
\hline
\end{tabular}

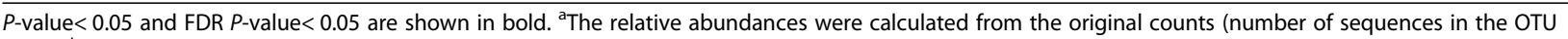
table). ${ }^{\mathrm{b}}$ Fold changes were calculated from the GLM, which corrects for differences in library size between the samples and the effects of confounding factors. It is therefore not possible to derive these fold changes from the original counts (number of sequences in the OTU table) by simple algebraic calculations

bacteria per $\mathrm{mL}$ of intestinal content in the duodenum and jejunum to $10^{8}$ bacteria per $\mathrm{mL}$ in the ileum, compared to $10^{11}$ bacteria per gram of wet stool in the colon $[12,13]$. In addition to having low bacterial biomass, duodenal luminal contents are viscous due to the mucus layer present in the small intestine $[14,15]$, and require special handling during sample collection and processing prior to culture and DNA extraction, in order to increase the likelihood of the assessment of all microbial communities, including those associated with the mucus layer.

In the assessment of the microbiome, it is essential to accurately and completely assess the microbial components in a sample. Although standards have been set for the assessment of the stool microbiome, these standards have not been assessed for small intestinal fluid assessment. Mucous in general is a viscous fluid that can trap bacteria in its matrix and previous studies performed with sputum samples have shown that treating this viscosity has an impact on the microbial assessment $[5,16]$. However, until now, no studies have investigated the impact on microbial assessment and DNA recovery in aspirates collected from small bowel. There are agents known to safely and effectively improve microbial assessment and DNA yield in viscous samples, and one such agent is DTT, which can reduce the disulfide bonds between mucin subunits.

In this study we established a methodology to improve microbial DNA recovery from small bowel aspirates, which includes different sample processing steps when compared to conventionally published methods for extracting DNA for microbiome assessment of gut materials such as stool [17-19]. The concentrations of DNAs extracted from DA ranged from very low levels to up to $70 \mathrm{ng} / \mathrm{ml}$ when samples were pretreated with DTT, more than 3-fold higher than those from samples which were not pretreated with the reducing agent. Initial DNA concentrations exhibited a higher positive correlation with those of the final V3/V4 libraries for DTT-pretreated DA compared to non-pretreated DA, which may indicate a specific increase in the isolation of bacterial DNAs. The use of a fixed initial DNA concentration during the preparation of sequencing libraries from DA should be carefully analyzed, and the addition of DTT during sample processing and for removal of the All Protect reagent is highly recommended as this increases

Table 4 Differential abundance of members of the family Enterobacteriaceae in DA-DTT versus DA-U

\begin{tabular}{|c|c|c|c|c|c|}
\hline \multirow[b]{2}{*}{ Taxonomy } & \multicolumn{5}{|c|}{ DA-DTT $(n=43)$ vs. DA-U $(n=112)$} \\
\hline & $\begin{array}{l}\text { Average relative } \\
\text { abundance \% } \\
\text { DA-DTT }\end{array}$ & $\begin{array}{l}\text { Average relative } \\
\text { abundance \% } \\
\text { DA-U } U^{a}\end{array}$ & $\begin{array}{l}\text { Fold Change } \\
\text { (calculated from } \\
\text { the GLM) }\end{array}$ & $P$-value & $\begin{array}{l}\text { FDR } \\
P \text {-value }\end{array}$ \\
\hline $\begin{array}{l}\text { C_Gammaproteobacteria, o_Enterobacteriales, } \\
\text { f_Enterobacteriaceae }\end{array}$ & 19.193 & 6.068 & 5.46 & $5.13 E-4$ & $1.47 \mathrm{E}-3$ \\
\hline f_Enterobacteriaceae, g_unknown & 14.984 & 5.227 & 17.00 & $2.72 \mathrm{E}-8$ & $1.21 \mathrm{E}-7$ \\
\hline f_Enterobacteriaceae, g_Klebsiella & 3.812 & 0.784 & 24.10 & $7.13 E-7$ & $2.73 \mathrm{E}-6$ \\
\hline f_Enterobacteriaceae, g_Providencia & 0.224 & 0.00025 & 13.57 & $<0.0001$ & $<0.0001$ \\
\hline f_Enterobacteriaceae, g_Morganella & 0.018 & 0.006 & 36.71 & $1.18 \mathrm{E}-9$ & $5.81 \mathrm{E}-9$ \\
\hline f_Enterobacteriaceae, g_Salmonella & 0.006 & 0.001 & 3.71 & 0.01 & 0.02 \\
\hline
\end{tabular}

$P$-value $<0.05$ and FDR $P$-value $<0.05$ are shown in bold. ${ }^{a}$ The relative abundances were calculated from the original counts (number of sequences in the OTU table). ${ }^{b}$ Fold changes were calculated from the GLM, which corrects for differences in library size between the samples and the effects of confounding factors. It is therefore not possible to derive these fold changes from the original counts (number of sequences in the OTU table) by simple algebraic calculations 

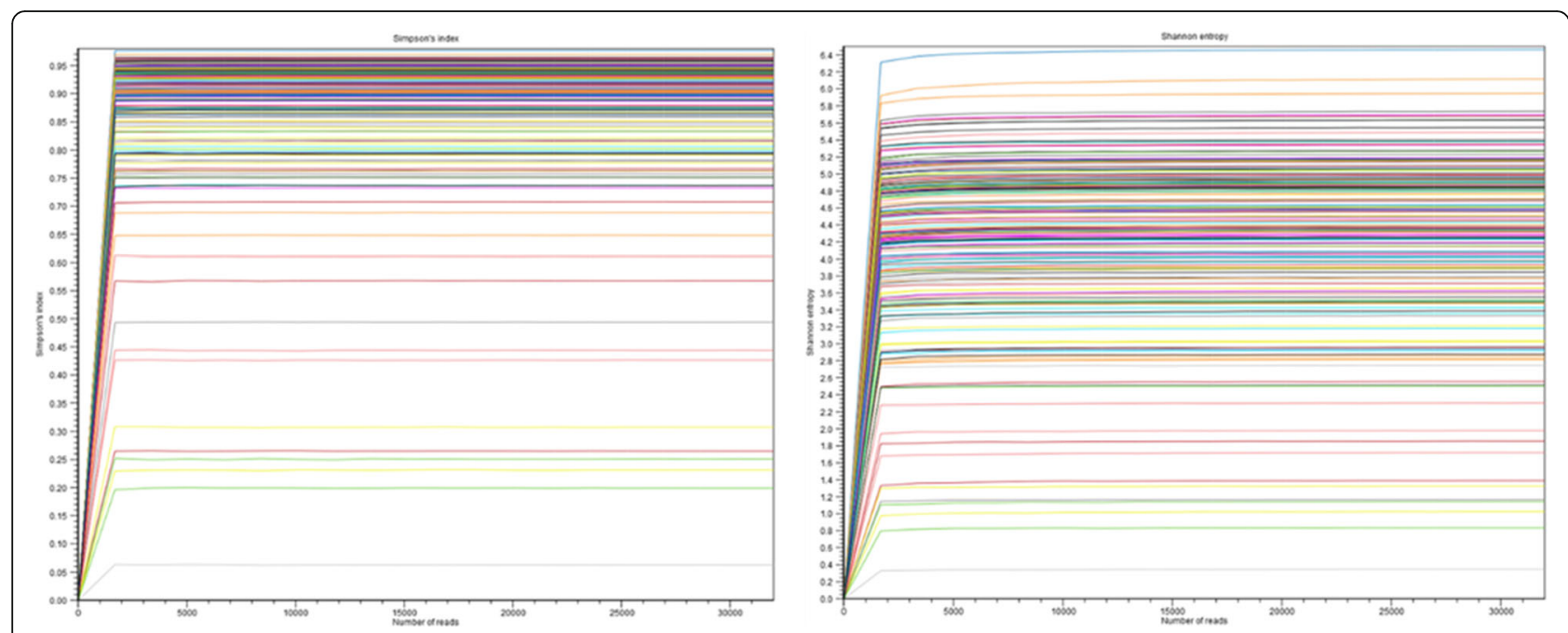

Fig. 5 Alpha diversity rarefaction curves for DA-DTT $(N=112)$ and DA-U $(N=43)$ samples. Samples were rarefied to the least numbers of sequences obtained

the initial yield of microbial DNA prior sequencing library preparation.

In addition to increases in DNA yields and library concentrations, DA processed with DTT prior to microbial culture exhibited higher numbers of bacterial colonies on blood agar plates incubated under anaerobic conditions. The relative abundance of specific obligate and facultative anaerobes detected in DA-DTT was increased compared to DA-U samples, which may reflect the increased detection of microbes associated with the mucus layer. For example, the relative abundance of the genus Enterococcus (phylum Firmicutes) detected in DA-DTT was significantly increased. This genus comprises over 50 Gram-positive facultative anaerobic lactic acid cocci species isolated from numerous environments, including the human GI tract [20]. Enterococcus species constitute up to $1 \%$ of the gut microbiota, and most species can grow on blood agar plates under anaerobic conditions. The relative abundance of the genus Clostridium (phylum Firmicutes), which is comprised of obligate anaerobes and some aerotolerant species, detected in DADTT samples was also increased.

The relative abundance of the genus Bacteroides, comprised of Gram-negative obligately anaerobic bacilli, detected in DA-DTT was also significantly increased compared to DA-U samples. Species from this genus can grow on blood agar and are well-adapted to the gastrointestinal tracts of mammals, including humans $[21,22]$. The human large intestine is densely colonized with species from the genus Bacteroides (phylum Bacteroidetes) [23], many of which perform essential metabolic functions for the host, including the metabolism of

\section{Shannon diversity}

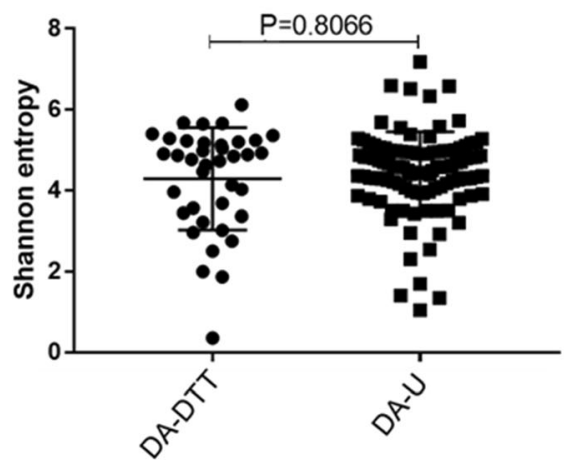

\section{Simpson's diversity}

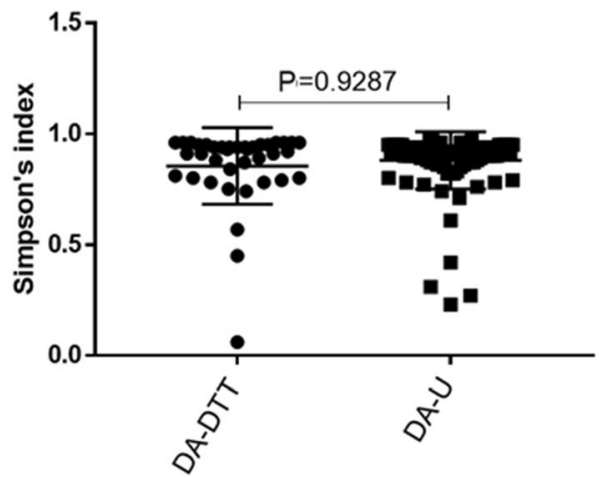

Fig. 6 Alpha diversity indices of DA samples pre-treated with DTT (DA-DTT, $N=112)$ and untreated DA (DA-U, $N=43)$. Left: Shannon entropy diversity for DA-DTT and DA-U samples. Right: Simpson's index diversity for DA-DTT and DA-U samples 


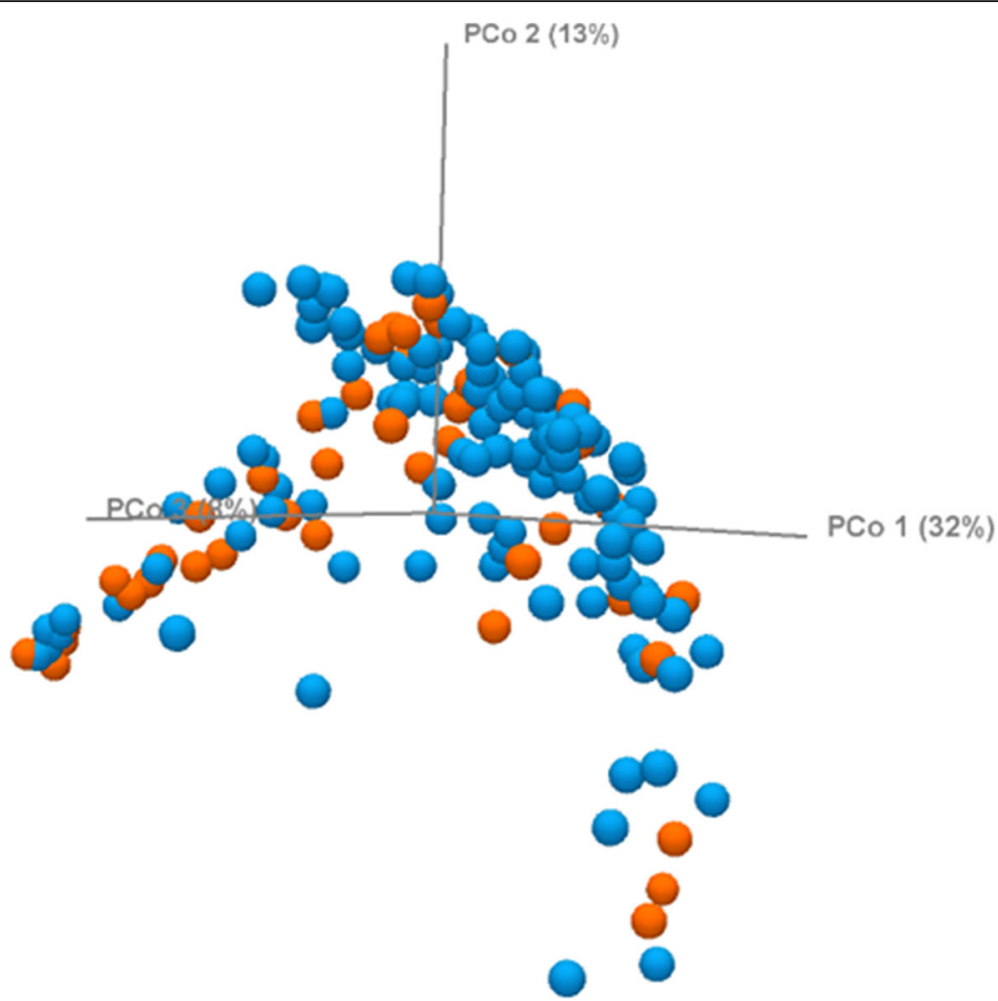

Fig. 7 Beta diversity of DA-U and DA-DTT based on the weighted UniFrac metric. Principal Coordinates Analysis plot of binary and abundanceweighted Unifrac distances between DA-DTT (shown in orange, $N=43$ ) and DA- $U$ (shown in blue, $N=112$ )

proteins and complex sugars. In contrast, the small intestine is not as heavily colonized by members of the phylum Bacteroidetes, which comprised less than $4 \%$ of the total microbes detected in DA-U. With the addition of the reducing agent DTT, which breaks the disulfide bonds linking mucin subunits in mucus prior to microbial culture and DNA extraction, the relative abundance of Bacteroidetes detected in DA increased significantly from 4 to $7 \%$, indicating a possible role for species from this phylum in mucus metabolism. Mucus is a dynamic matrix, consisting of mucin glycoproteins secreted by intestinal goblet cells, which lubricates the transit of intestinal contents, amongst other functions. Mucus glycoproteins can be used as a carbon source by many asaccharolytic microorganisms, and the low oxygen levels at atmospheric pressures allow the colonization and growth of anaerobes in mucus [24, 25].

The phylum Proteobacteria also includes aerotolerant asaccharolytic microorganisms that require proteinaceous substrates as carbon and energy sources, such as Campylobacter [26], as well as facultative anaerobes from the family Enterobacteriaceae included in the "Mucosally Associated Consortium" in the colon described by Albenberg et al. [24]. Pretreatment of DA with DTT increases the detected relative abundance of many Enterobacteriaceae members, including the clinically important genera Klebsiella, Providencia and Salmonella as well as unknown members. Providencia and Salmonella include motile species that can adhere to mucus and epithelial cells and actively invade the host epithelium [27-29]. The relative abundance of the genus Pseudomonas, detected in DA-DTT was also increased compared to non-pretreated DA. Members of this genus, including the most studied species $P$. aeruginosa, are also motile and can be part of the normal human microflora, but are also important clinically as they are known to cause hospital-acquired infections such as pneumonia and urinary tract infections [30].

A limitation of this study was that DTT treatment vs. non-treatment could not be tested in different portions of the same samples. This was partly due to the small sizes of the individual samples, and partly due to the fact that their viscosity made it impossible to divide them evenly. We have attempted to compensate for this through the number of samples tested.

Surprisingly, the changes in several microbial taxa in DA samples after the addition of DTT did not affect the overall microbial diversity. These findings further suggest that the addition of the reducing agent DTT improves microbial assessment and DNA recovery without causing a dramatic change in the microbial balance in the aspirate samples. 


\section{Conclusions}

This study validates methodology to optimize yield for culture, and for DNA extraction for analysis of the small bowel microbiome. Culture totals, microbial DNA and microbiome analysis demonstrate marked differences with this new technique. This suggests that conventional techniques for DNA isolation provide an incomplete picture of the microbial environment in the small bowel. Thus, this new technique appears ideal for small bowel microbiome assessment.

\section{Methods}

The REIMAGINE study is a large-scale study designed to examine the relationship between the small bowel microbiome in human health and disease. In brief, the study involves collecting data in consecutive patients undergoing routine upper gastrointestinal endoscopy (esophagogastroduodenoscopy). After a battery of questionnaires for comprehensive collection of health information, and obtaining serum and genetic samples, the endoscopy entailed the collection of small bowel aspirates and two mucosal biopsies. The first phase of this study was to develop, validate and optimize small intestinal aspiration techniques, and microbial sample acquisition.

\section{Study subjects}

Male and female subjects aged 18-85 undergoing esophagogastroduodenoscopy (EGD) without colon preparation for standard of care purposes were prospectively recruited for this study. Potential participants were identified by study staff and their eligibility was verified by co-investigators or the PI. Although there are no exclusion criteria for the REIMAGINE study, small bowel biopsies are not collected from subjects with bleeding disorders or advanced cirrhosis of the liver with coagulopathy and intestinal varices where the international normalized ratio (INR) was greater than 1.5 , in order to minimize the risk of bleeding from the biopsy site. The REIMAGINE study protocol was approved by the Institutional Review Board at Cedars-Sinai Medical Center, and all subjects provided informed written consent prior to participating in the study. Samples from subjects taking antibiotics were not included in the present study.

\section{Study procedures}

\section{Small intestinal sample procurement}

During EGD, samples of luminal fluid $(\sim 2 \mathrm{ml})$ were obtained from the duodenum using a custom sterile aspiration catheter (Hobbs Medical, Inc.). The custom catheter consisted of a newly designed double lumen sterile catheter, with the inner lumen maintaining sterility during insertion by applying sterile bone wax into the open tip of the external catheter. During endoscopy, the endoscopist is instructed to immediately enter the duodenum and insert the aspiration catheter. The inner catheter then dislodges the bone wax, exposing the sterile inner catheter. This inner catheter is used to aspirate duodenal fluid through lasered side holes to acquire a volume of $2 \mathrm{~mL}$. These precautions eliminated the risk of oral and gastric contamination.

\section{Aspirate processing}

Immediately after aspiration, samples from all duodenal aspirates were cultured on MacConkey agar (Becton Dickinson, Franklin Lakes, NJ, EUA) and blood agar (Becton Dickinson) for determination of the number of colony-forming units (CFU) per $\mathrm{mL}$ of aspirate. To assess the effect of viscosity on culture, a subset of aspirates were not pretreated and simply cultured (the DA-U group for "untreated") and another subset were first pretreated with the reducing agent Dithiothreitol (DTT) (Sputolysin ${ }^{\circ}$ Reagent, Cat. 560,000-1SET, EMD Millipore Corp, Billerica, MA, USA) (the DA-DTT group) (see Fig. 1).

For DA-DTT samples, 1x DTT (6.5 mM dithiothreitol in $100 \mathrm{mM}$ phosphate buffer, $\mathrm{pH} 7.0$ ) was added to an aliquot of the DA in a 1:1 ratio and the resulting mixture was vortexed until the sample was liquified (typically 30 s). $100 \mu \mathrm{L}$ of the liquified mixture was serially diluted with $900 \mu \mathrm{L}$ sterile $1 \mathrm{x}$ PBS and samples of the 1:10 and 1:100 dilutions were plated in duplicate on MacConkey agar under aerobic conditions for the quantitation of Gram-negative bacilli, and on blood agar under anaerobic conditions for the quantitation of total anaerobes. For DA-U samples, $100 \mu \mathrm{L}$ of DA was diluted directly with $900 \mu \mathrm{L}$ sterile $1 \mathrm{x}$ PBS and samples of the 1:10 and 1:100 dilutions were plated as described above. All plates were incubated at $37^{\circ} \mathrm{C}$ for $16-18 \mathrm{~h}$, after which colonies were electronically counted using the Scan 500 (Interscience, Paris, France). As a negative control, $100 \mu \mathrm{L}$ of 1x DTT was also cultured aerobically on MacConkey agar and anaerobically on blood agar. All dilution factors were taken into account for final determination of microbial burden.

After aliquots for microbial culture were taken, remaining DA-U and DA-DTT samples were centrifuged at high speed $(17,136 \mathrm{x} \mathrm{g})$ for $10 \mathrm{~min}$ and the supernatant was carefully removed and stored at $-80{ }^{\circ} \mathrm{C}$ for future metabolomic analyses. $500 \mu \mathrm{L}$ of sterile All Protect reagent (Qiagen, Hilden, Germany) was added to each pellet for stabilization of DNA, RNA and proteins, and the pellets were stored at $-80^{\circ} \mathrm{C}$ prior to DNA isolation and analysis of the DA microbiome.

\section{DNA extraction and quantification from aspirates}

DA-U and DA-DTT samples were thawed on ice and $1 \mathrm{x}$ DTT was added in a 1:1 ratio, after which the samples 
were vortexed until the All Protect reagent was fully liquefied (around 30s). DNA extraction was then performed for both groups using the MagAttract PowerSoil DNA KF Kit (Qiagen, cat. No. 27000-4-KF) with some modifications. DNA extraction was also performed on negative control samples (1x DTT) as a control.

The lysis step was carried out by adding garnet beads (Qiagen, cat. No. 13123-50) and $746 \mu \mathrm{L}$ PowerBead Solution to each pellet-containing tube, followed by $4 \mu \mathrm{L}$ RNase A and $60 \mu \mathrm{L}$ SL Solution (Lysis buffer) in this specific order. Tubes were sealed with parafilm, vortexed horizontally for $15 \mathrm{~min}$, and then centrifuged for $6 \mathrm{~min}$ at $4500 \mathrm{x} \mathrm{g}$. The supernatants were transferred to new tubes containing $450 \mu \mathrm{L}$ IR Solution, vortexed for $3 \mathrm{~s}$, incubated at $4{ }^{\circ} \mathrm{C}$ for $10 \mathrm{~min}$, and then centrifuged for 6 $\mathrm{min}$ at $4500 \mathrm{xg}$. The supernatants were transferred to new tubes and centrifuged for a further $6 \mathrm{~min}$ at $4500 \mathrm{x}$ g. $450 \mu \mathrm{L}$ of the resulting supernatants were added to deep 96-well KingFisher plates containing magnetic beads and DNA extraction was performed using the KingFisher Duo (Thermo Fisher Scientific, Waltham, MA, USA). The final DNA volume was $100 \mu \mathrm{L}$. DNAs were then quantified using Qubit ds DNA BR Assay kits (Invitrogen by Thermo Fisher Scientific, Waltham, MA, USA) on a Qubit 4 Fluorometer (Invitrogen).

\section{Library preparation and 165 rRNA gene sequencing}

$16 \mathrm{~S}$ library preparation for DNAs from all groups was performed according to the Illumina (Illumina, San Diego, CA, USA) protocol https://support.illumina.com/docu ments/documentation/chemistry_documentation/16s/16s -metagenomic-library-prep-guide-15044223-b.pdf, with some modifications. The V3 and V4 regions were amplified using the gene-specific primers S-D-Bact-0341-b-S-17 and S-D-Bact-0785-a-A-21 published and validated by Klindworth et al. [31]. The primers were modified in accordance with the protocol by adding the Illumina sequencing adapters to each one.

The full-length primer sequences used were:

16S amplicon PCR forward primer: 5'TCGTCGGCA GCGTCAGATGTGTATAAGAGACAGCCTACGGGN GGCWGCAG

16S amplicon PCR reverse primer: 5'GTCTCGTGG GCTCGGAGATGTGTATAAGAGACAGGACTACVH GGGTATCTAATCC

The 16S library preparation protocol was modified as follows: $5 \mu \mathrm{L}$ of DNA was added to a Master Mix $(0.5 \mu \mathrm{L}$ of $10 \mu \mathrm{M}$ 16S Amplicon PCR Forward primer, $0.5 \mu \mathrm{L}$ of $10 \mu \mathrm{M}$ 16S Amplicon PCR Reverse primer, $12.5 \mu \mathrm{L} 2 \mathrm{x}$ KAPA HiFi HotStart ReadyMix and $6.5 \mu \mathrm{L}$ of molecular grade $\mathrm{PCR} \mathrm{H}_{2} \mathrm{O}$ ) and the PCR was performed as follows:

1. Initial denaturation step at $95^{\circ} \mathrm{C}$ for $3 \mathrm{~min}$
2. 27 cycles of: $95^{\circ} \mathrm{C}$ for $30 \mathrm{~s}, 55^{\circ} \mathrm{C}$ for $30 \mathrm{~s}$ and $72{ }^{\circ} \mathrm{C}$ for $30 \mathrm{~s}$

3. $72^{\circ} \mathrm{C}$ for $5 \mathrm{~min}$

4. Hold at $4{ }^{\circ} \mathrm{C}$

An optimized Clean-Up step was performed with Agencourt AMPure XP beads using the modifications proposed by Quail et al. [32]. After adding the beads to each Amplicon PCR 96-well plate on the magnetic stand, samples were incubated for five minutes followed by two wash steps with $80 \%$ ethanol. The beads were air dried for five minutes. After removing the plate from magnetic stand, beads were incubated with EB Buffer (Qiagen) for five minutes to elute the DNA. The plate was placed back on the magnetic stand and after 2-3 min the supernatant was transferred to an empty clean well, preventing the transfer of the beads with the supernatant.

Five $\mu \mathrm{L}$ of the final Amplicon PCR product was used for the Index PCR, which was performed using the Nextera XT Index kit and 2x KAPA HiFi HotStart ReadyMix, following the Illumina protocol for 8 cycles. After a second modified Clean-Up step, the final product was quantified using Qubit ds DNA BR Assay kits and Qubit 1X dsDNA HS Assay kits on a Qubit 4 Fluorometer and analyzed using Agilent DNA 1000 chips (Agilent Technologies, Santa Clara, CA) and Agilent HS DNA chips (Agilent) on an Agilent 2100 Bioanalyzer System.

\section{$16 \mathrm{~S}$ rRNA gene sequencing and analysis}

The V3 and V4 libraries prepared using DNAs from DA-DTT and DA-U groups were sequenced using a MiSeq Reagent Kit v3 (600-cycles) on a MiSeq System (Illumina, San Diego, California). $2 \times 301$ cycles pairedend sequencing was performed according to manufacturer's protocol and 5\% Phix (Illumina) was added to each library pool.

Operational Taxonomic Unit (OTU) clustering and taxonomic analyses were performed using CLC Genomics Workbench v. 10.1.1 and CLC Microbial Genomics Module v. 2.5 (Qiagen). Sequences were first trimmed to remove 13 bases at the $5^{\prime}$ terminal position and merged considering the alignment scores as follows: mismatch cost of 2, gap cost of 2, zero maximum unaligned end mismatches and minimum score of 30 . After merging, sequences were clustered into OTUs at $97 \%$ sequence similarity level using the Amplicon-Based OTU clustering tool. The creation of new OTUs was allowed considering 97\% taxonomic similarity. The most abundant sequences were selected as representative of each cluster, and then assigned to a taxonomy level using CLC Microbial Genomics default values and the Greengenes Database 2013 release. Alpha diversity indexes (Chao1, Simpson and Shannon) were calculated using the 
Abundance Analysis tool. The weighted Unifrac metric was used to calculate inter-sample diversity (beta diversity).

\section{Statistical analysis}

Multiple comparisons and statistical analyses were performed using CLC Genomics Workbench v. 10.1.1 and CLC Microbial Genomics Module v. 2.5 (Qiagen). A Negative Binomial Generalized Linear Model (GLM) model was used to obtain maximum likelihood estimates for an OTU's log-fold change between two conditions, and the Wald test was used to determine significance, as part of the CLC package available at https://www.qiagenbioinformatics.com/products/clc-genomics-workbench/. False Discovery Rate (FDR) was performed to correct $P$ values. Fold changes are calculated from the GLM, which corrects for differences in library size between the samples and the effects of confounding factors. Again, these calculations were performed using the CLC package. It is therefore not possible to derive these fold changes from the original counts by simple algebraic calculations. Two-tailed Spearman $\mathrm{r}$ correlations, MannWhitney tests and graph construction were performed using GraphPad Prism 7.02 (GraphPad Software, La Jolla, CA, USA). For statistical analysis purposes only, no growth on blood agar and MacConkey agar $(\mathrm{CFU} / \mathrm{ml}=$ 0 ) was assigned as $1 \mathrm{CFU} / \mathrm{ml}$.

\section{Supplementary information}

Supplementary information accompanies this paper at https://doi.org/10. 1186/s12866-019-1617-1.

Additional file 1. Title of data: Culture data, sequenced samples information and OTU table. Description of the data: the culture data section (sheet 1) shows the number of bacterial colonies observed on MacConkey agar (incubated aerobically) and blood agar (incubated anaerobically) for all DA-DTT $(N=101)$ and DA-U $(N=127)$ samples. Data are presented as CFU/mL of duodenal aspirate. The sequenced samples information section (sheet 2) provides data for the sequenced DA-DTT $(\mathrm{N}=43)$ and $\mathrm{DA}-\mathrm{U}(\mathrm{N}=112)$ samples, including the number of bacterial colonies observed on MacConkey agar and blood agar (in CFU/mL of duodenal aspirate), initial DNA concentration, library concentration and library size (number of sequences). The OTU table section (sheet 3) contains the OTU table generated from the sequenced DA-DTT $(\mathrm{N}=43)$ and DA-U $(N=112)$ samples. The table provides the OTU numbers, taxonomic classification, number of reads for each OTU and the OTU sequence.

Additional file 2. Title of data: V3-V4 165 rRNA library size of DA-DTT and DA-U samples. Description of the data: library sizes (number of sequences in the OTU table) for DA-DTT and DA- $U$ samples. The table provides the library size mean, standard deviation, standard error of the mean, median, 25 and $75 \%$ percentiles.

\section{Abbreviations}

CFU: Colony-forming units; DA: Duodenal aspirates; DA-DTT: Duodenal aspirates pretreated with dithiothreitol; DA-U: Duodenal aspirates untreated; DNA: Deoxyribonucleic acid; DTT: Dithiothreitol;

EGD: Esophagogastroduodenoscopy; FC: Fold change; FDR: False discovery rate; Gl: Gastrointestinal; GLM: Generalized linear model; INR: International normalized ratio; Med: Median; OTU: Operational taxonomic unit; PCR: Polymerase chain reaction; REIMAGINE study: Revealing the Entire
Intestinal Microbiota and its Associations with the Genetic, Immunologic, and Neuroendocrine Ecosystem study; rRNA: ribosomal ribonucleic acid

\section{Acknowledgements}

Not applicable.

\section{Authors' contributions}

RM and MP conceived and designed the study, reviewed the data and wrote and edited the manuscript. AR assisted with study design and planning, analyzed the data, and reviewed and edited the manuscript. RS recruited subjects and RS and SC processed the small intestinal samples. GL, GP, WM, SW, and GB performed the laboratory experiments, GL, AR and MP analyzed the data, and GL, GB RM and MP wrote and edited the manuscript. All authors read and approved the final manuscript.

\section{Funding}

This study was supported in part by a grant from the Monica Lester Charitable Trust to Dr. Ruchi Mathur. This funding body played no role in the design of the study, in the collection, analysis, and interpretation of data, or the writing of the manuscript.

\section{Availability of data and materials}

The datasets generated during the current study are available in the National Center for Biotechnology Information (NCBI) BioProject Repository https:// www.ncbi.nlm.nih.gov/bioproject under BioProject ID PRJNA520899.

\section{Ethics approval and consent to participate}

The study protocol was approved by the Institutional Review Board at Cedars-Sinai Medical Center (Pro00035192), and all subjects provided informed written consent prior to participating in the study.

\section{Consent for publication}

Not applicable.

\section{Competing interests}

The authors declare that they have no competing interests.

\section{Author details}

${ }^{1}$ Medically Associated Science and Technology (MAST) Program, Cedars-Sinai Medical Center, Los Angeles, CA, USA. ²Division of Endocrinology, Diabetes, and Metabolism, Cedars-Sinai Medical Center, Los Angeles, CA, USA. ${ }^{3}$ Division of Digestive and Liver Diseases, Cedars-Sinai Medical Center, Los Angeles, CA, USA.

Received: 9 March 2019 Accepted: 20 October 2019

Published online: 01 November 2019

\section{References}

1. Turnbaugh PJ, Ley RE, Hamady M, Fraser-Liggett CM, Knight R, Gordon Jl. The human microbiome project. Nature. 2007;449:804-10.

2. Costello EK, Lauber CL, Hamady M, Fierer N, Gordon Jl, Knight R. Bacterial community variation in human body habitats across space and time. Science. 2009;326:1694-7.

3. Hillman ET, Lu H, Yao T, Nakatsu CH. Microbial ecology along the gastrointestinal tract. Microbes Environ. 2017;32:300-13.

4. Minich JJ, Zhu Q, Janssen S, Hendrickson R, Amir A, Vetter R, et al. KatharoSeq Enables High-Throughput Microbiome Analysis from LowBiomass Samples. mSystems. 2018;3.

5. Oriano M, Terranova L, Teri A, Sottotetti S, Ruggiero L, Tafuro C, et al. Comparison of different conditions for DNA extraction in sputum - a pilot study. Multidiscip Respir Med. 2019;14:6.

6. McMurdie PJ, Holmes S. Waste not, want not: why rarefying microbiome data is inadmissible. PLoS Comput Biol. 2014;10:e1003531.

7. Weiss S, Xu ZZ, Peddada S, Amir A, Bittinger K, Gonzalez A, et al. Normalization and microbial differential abundance strategies depend upon data characteristics. Microbiome. 2017;5:27.

8. Glassing A, Dowd SE, Galandiuk S, Davis B, Chiodini RJ. Inherent bacterial DNA contamination of extraction and sequencing reagents may affect interpretation of microbiota in low bacterial biomass samples. Gut Pathog. 2016;8:24. 
9. Williams KP, Gillespie JJ, Sobral BW, Nordberg EK, Snyder EE, Shallom JM, et al. Phylogeny of gammaproteobacteria. J Bacteriol. 2010;192:2305-14.

10. Kolling G, Wu M, Guerrant RL. Enteric pathogens through life stages. Front Cell Infect Microbiol. 2012;2:114.

11. Cox KD, Black MJ, Filip N, Miller MR, Mohns K, Mortimor J, et al. Community assessment techniques and the implications for rarefaction and extrapolation with hill numbers. Ecol Evol. 2017;7:11213-26.

12. Leser TD, Molbak L. Better living through microbial action: the benefits of the mammalian gastrointestinal microbiota on the host. Environ Microbiol. 2009;11:2194-206.

13. Sender R, Fuchs S, Milo R. Revised estimates for the number of human and Bacteria cells in the body. PLoS Biol. 2016;14:e1002533.

14. Johansson ME, Sjovall H, Hansson GC. The gastrointestinal mucus system in health and disease. Nat Rev Gastroenterol Hepatol. 2013;10:352-61.

15. Ermund A, Schutte A, Johansson ME, Gustafsson JK, Hansson GC. Studies of mucus in mouse stomach, small intestine, and colon. I. Gastrointestinal mucus layers have different properties depending on location as well as over the Peyer's patches. Am J Physiol Gastrointest Liver Physiol. 2013;305:G341-7.

16. Terranova L, Oriano M, Teri A, Ruggiero L, Tafuro C, Marchisio P, et al. How to process sputum samples and extract bacterial DNA for microbiota analysis. Int J Mol Sci. 2018;19.

17. Jovel J, Patterson J, Wang W, Hotte N, O'Keefe S, Mitchel T, et al. Characterization of the gut microbiome using $16 \mathrm{~S}$ or shotgun Metagenomics. Front Microbiol. 2016;7:459.

18. Wang Z, Zolnik CP, Qiu Y, Usyk M, Wang T, Strickler HD, et al. Comparison of fecal collection methods for microbiome and metabolomics studies. Front Cell Infect Microbiol. 2018;8:301.

19. Jones MB, Highlander SK, Anderson EL, Li W, Dayrit M, Klitgord N, et al. Library preparation methodology can influence genomic and functional predictions in human microbiome research. Proc Natl Acad Sci U S A. 2015; 112:14024-9.

20. Dubin K, Pamer EG. Enterococci and their interactions with the intestinal microbiome. Microbiol Spectr. 2014;5.

21. Ley RE, Hamady M, Lozupone C, Turnbaugh PJ, Ramey RR, Bircher JS, et al. Evolution of mammals and their gut microbes. Science. 2008;320:1647-51.

22. Eckburg PB, Bik EM, Bernstein CN, Purdom E, Dethlefsen L, Sargent M, et al. Diversity of the human intestinal microbial flora. Science. 2005;308:1635-8.

23. Rajilic-Stojanovic M, de Vos WM. The first 1000 cultured species of the human gastrointestinal microbiota. FEMS Microbiol Rev. 2014;38:996-1047.

24. Albenberg L, Esipova TV, Judge CP, Bittinger $K$, Chen J, Laughlin A, et al. Correlation between intraluminal oxygen gradient and radial partitioning of intestinal microbiota. Gastroenterology. 2014;147:1055-63 e1058.

25. Li H, Limenitakis JP, Fuhrer T, Geuking MB, Lawson MA, Wyss M, et al. The outer mucus layer hosts a distinct intestinal microbial niche. Nat Commun. 2015;6:8292.

26. van der Stel AX, van de Lest CHA, Huynh S, Parker CT, van Putten JPM, Wosten M. Catabolite repression in campylobacter jejuni correlates with intracellular succinate levels. Environ Microbiol. 2018;20:1374-88.

27. O'Hara CM, Brenner FW, Miller JM. Classification, identification, and clinical significance of Proteus, Providencia, and Morganella. Clin Microbiol Rev. 2000;13:534-46.

28. Kurmasheva N, Vorobiev V, Sharipova M, Efremova T, Mardanova A. The potential virulence factors of Providencia stuartii: motility, adherence, and invasion. Biomed Res Int. 2018;2018:3589135.

29. Elhadad D, Desai P, Rahav G, McClelland M, Gal-Mor O. Flagellin is required for host cell invasion and Normal Salmonella Pathogenicity Island 1 expression by Salmonella enterica Serovar Paratyphi a. Infect Immun. 2015; 83:3355-68.

30. Lister PD, Wolter DJ, Hanson ND. Antibacterial-resistant Pseudomonas aeruginosa: clinical impact and complex regulation of chromosomally encoded resistance mechanisms. Clin Microbiol Rev. 2009;22:582-610.

31. Klindworth A, Pruesse E, Schweer T, Peplies J, Quast C, Horn M, et al. Evaluation of general $16 \mathrm{~S}$ ribosomal RNA gene PCR primers for classical and nextgeneration sequencing-based diversity studies. Nucleic Acids Res. 2013;41:e1.

32. Quail MA, Swerdlow H, Turner DJ. Improved protocols for the illumina genome analyzer sequencing system. Curr Protoc Hum Genet. 2009; Chapter 18: Unit 1812

\section{Publisher's Note}

Springer Nature remains neutral with regard to jurisdictional claims in published maps and institutional affiliations.

Ready to submit your research? Choose BMC and benefit from:

- fast, convenient online submission

- thorough peer review by experienced researchers in your field

- rapid publication on acceptance

- support for research data, including large and complex data types

- gold Open Access which fosters wider collaboration and increased citations

- maximum visibility for your research: over $100 \mathrm{M}$ website views per year

At BMC, research is always in progress.

Learn more biomedcentral.com/submissions 